\title{
CARNAVALES Y NACIÓN. ESTUDIO SOBRE BRASIL, COLOMBIA, COSTA RICA, CUBA Y VENEZUELA DE MARCO GONZÁLEZ PÉREZ (COMPILADOR). BOGOTÁ, CORPORACIÓN DE ESTUDIOS INTERCULTURALES APLICADOS, 2014, 284 PÁGINAS
}

\author{
CARNIVAL AND NATION. STUDY ON BRAZIL, COLOMBIA, COSTA RICA, CUBA AND \\ VENEZUELA DE MARCO GONZALEZ PEREZ (ED). BOGOTA CORPORATION APPLIED \\ INTERCULTURAL STUDIES, 2014, 284 PAGES
}

\section{John Alexander Castro Lozano ${ }^{1}$}

Marco González Pérez, en Carnavales y nación, reúne doce artículos de investigación, relacionando el carnaval con lo cultural, lo educativo, lo político y lo social. Estos artículos son elaborados por especialistas de Brasil, Colombia, Costa Rica, Cuba y Venezuela. El libro se divide en tres secciones. En la primera parte, El carnaval y lo político, se encuentran los trabajos de Juan Montoya y Gina Hidalgo. En la segunda parte, El carnaval y lo cultural, son presentados los documentos de Sonia García, Vera Gerner, Claudia Navas-Courbon, Virtudes Feliu, Otilia González, Emilio Mendoza, Felipe Ferreira, Jairo Soto, María Arcila y Luis López. En la tercera parte, $E l$ carnaval y lo simbólico, se reúnen los textos de Catalina Bohórquez y Eliana Medina.

Marco González, en Construir tejidos de nación: Los carnavales en Colombia, elabora un balance de las distintas fiestas realizadas en Colombia, algunas son acordes a la precuaresma y otras,

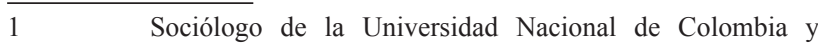
Magister en Estudios Sociales de la Universidad Pedagógica Nacional, Colombia. Correo: alexandercastro1981@gmail.com no. Algunas son expresiones patrimoniales y en otras, se participa, solamente, por diversión. No obstante, los carnavales se han alterado por la industria cultural pues son patrocinadas por la empresa privada, con un claro interés comercial. Asimismo, la diversidad de conflictos internos ha suspendido la realización de las fiestas en determinadas regiones de Colombia.

Juan Montoya, en El carnaval del poder, el poder de carnaval. Cali 1922-1936, describe el proceso, de principio a fin, de esa festividad, convocada para los cuatro últimos días del año y promocionada inicialmente por la elite caleña y los empresarios inmigrantes. En los primeros fastos excluyeron a los sectores pobres de la población en la preparación y participación de la festividad. No obstante, en sus dos últimos años su intervención fue mucho más amplia, incluyendo el elemento fundamental del carnaval: lo popular. Posteriormente, dejó de celebrarse.

Gina Hidalgo, en Cuando el pueblo quema al rey. Representaciones de la sublevación y de- 
nuncia en el desfile de años viejos del carnaval de blancos y negros de Pasto, destaca la quema del muñeco del "año viejo" como una forma de observar la muerte del año que termina. Este festejo se realiza el último día del año y se realiza en medio del consumo de licor, la comunión, la música y la ironía. En principio, el monigote es una propuesta familiar, es decir, es un ritual doméstico con desfiles barriales. El "año viejo" se ha transformado y sirve, también, para denunciar públicamente a los políticos locales, a través de la sátira. Por último, la quema es parte del calendario del precarnaval de blancos y negros de Pasto, Colombia.

Sonia García, en Diabluras de carnaval, expone las distintas versiones del diablo que emergen en las festividades y trascienden a aspectos vinculados con la música, la literatura, el deporte, las mentalidades, entre otros aspectos. La figura del demonio surgió con el proceso de colonización religiosa española y fue relacionada con el mal. Sin embargo, Satán se arraigó, especialmente, en las poblaciones con presencia de africanos y se integró a la cultura popular, particularmente, de los países caribeños. El maligno se ha representado y se ha denominado de diferentes maneras y su aparición puede revelar los conflictos sociales entre el dominador y el dominado.

Vera Gerner, en Las comparsas limonenses: música, contexto social e identidades, explica la semejanza entre las nociones y las prácticas del carnaval y las comparsas en Puerto Limón, Costa Rica. Los desfiles se realizan en el ambiente de las Fiestas Cívicas como un resultado histórico de las migraciones (afrodescendientes y mestizas) y de la creciente participación de población marginal en los ensayos. Las comparsas se caracterizan por la música, la danza, los elementos visuales, expresiones escénicas y aspectos sociales.

Claudia Navas, en Fiesta de los matachines, rastrea los posibles antecedentes de la festividad del Municipio de Guapí, Cauca, Colombia. La Fiesta del Matachín se lleva a cabo el 28 de di- ciembre, el día de los Santos Inocentes o de los locos, una fiesta pagana y católica. Esta celebración puede ser el resultado de festividades anteriores como los Saturnales y Lupercales, Corpus Christi y Santos Inocentes. Asimismo, la figura del Matachín tiene su origen en celebraciones amerindias, africanas, europeas y asiáticas. Esos festejos fueron adoptados y adaptados por el cristianismo en su calendario como parte del proceso colonizador. De ese modo, lograron confluir el paganismo y el catolicismo, de la pompa a la procesión. El Matachín es una figura que encarna distintos representaciones: religiosa, burlesca, teatral, irreverente, aguerride invertido. El Matachín es una figura que se transforma y se adecua a través del tiempo, los territorios y las poblaciones.

Virtudes Feliu, en El complejo carnavalesco cubano: Rescate y renovación de una tradición, muestra la importancia de las festividades en la identidad cultural de Cuba pues son parte de la idiosincrasia, la cultura popular y la religiosidad de la población. Las etapas de las celebraciones se manifiestan con la integración de los migrantes provenientes de Europa, Asia, África, Estados Unidos y Antillas. Además, de expresarse en los vestuarios, las danzas y la música.

Otilia González y Emilio Mendoza, en El carnaval de El callao y El Calipso venezolano: Negociación entre tradición y turismo, presentan el dilema entre la conservación del patrimonio histórico y sociocultural y la promoción del turismo cultural como una atractivo de la región. La realización de las carnestolendas se asocia al calendario religioso y se inicia el 31 de diciembre con el grito del carnaval. Siguen las actividades de coronación de reinas, los desfiles de las comparsas escolares y de las Negras de los Mamarrachos. El desarrollo del carnaval tiene espectáculos diurnos y nocturnos. El género musical tradicional y específico de El Callao es El Calipso y se escucha en las comparsas temáticas y musicales. El Calipso describe a El Callao, le rinde homenaje a algunos personajes y utiliza 
el amor desde una óptica sexual. En los últimos años, El Calipso ha integrado instrumentos musicales modernos y se ha influenciado por el pop caribeño.

Felipe Ferreira, en Carnaval brasileiro: Lugar do contemporâneo, señala que los carnavales parecen una festividad inmutable, al conservar algunos elementos tradicionales. Sin embargo, son dinámicos y se transforman con el tiempo ya que redefinen sus formas de expresión y significado, expuestos en sus tres componentes básicos: Escolas de Samba e Arte, Trios Elétricos e Novas Sonoridades y Entrudos Cibernéticos. De ese modo, la identidad nacional brasilera se constituye desde sus festividades.

Jairo Soto, en Posibilidades pedagógicas del carnaval como referente para la formación ciudadana en el Distrito de Barranquilla, expone la tensión entre la educación y el carnaval. Aunque en el papel se promueve el reconocimiento de la diversidad cultural desde la escuela. En la práctica, la educación sigue encerrada en las aulas de clase, tratando temáticas descontextualizadas de las vida cotidiana de los estudiantes. En consecuencia, se promueve la apropiación del Carnaval de Barranquilla como un laboratorio pedagógico, con el objetivo de disfrutar la fiesta, al mismo tiempo que es utilizada para educar.

María Arcila y Luis López, en Carnavales en Antioquia: La iglesia y los grupos de poder regional ante la inversión social, muestran que las elites económicas, políticas y eclesiásticas de la región antioqueña han logrado contralar las formas de diversión en las festividades, al simbolizar una amenaza al orden establecido. Así, la transgresión sólo es una exhibición y la reinvención es, únicamente pasajera. En la Fiesta de los Diablitos en Santa Fe, las frecuentes prohibiciones en las prácticas del carnaval han disminuido su intensidad con el objetivo de conservar las "buenas costumbres". Y en las Fiestas del Maíz en Sonsón, la intención es fortalecer el imagi- nario de un origen europeo y blanco en un país mestizo.

Catalina Bohórquez, en La música como dimensión simbólica del Carnaval, resalta el carnaval como un contexto que posibilita salir de la cotidianidad e ir hacia el éxtasis, al lograr gozar de un sistema simbólico caracterizado por colores, olores, sonidos y sabores. Igualmente, la música deja a un lado al silencio e invita al movimiento, al iniciar la fiesta y ser cómplice de la risa. En algunas ocasiones, sirve para denunciar.

Eliana Medina, en Calabazo, cuna de bebida y ritual en el carnaval de Riosucio, revela la importancia del guarapo, una bebida tradicional embriagante y representativa de la región. Este licor se fermenta en un calabazo y simboliza la generación de libertad. En ese sentido, aparece la figura del diablo ya que él permite la liberación del pueblo. No obstante, el patrocinio de la empresa licorera privada pretende desplazar el consumo de guarapo. De esa manera, surgió la Liga de la Pernicia, "superhéroes" con un propósito: mantener al guarapo como bebida típica del Carnaval de Riosucio.

Finalmente, los artículos reunidos en el libro tienen el objetivo inicial de comprender las particularidades de la idiosincrasia, de la cultura popular y de elite; como constructores de nación a través de los carnavales. Igualmente, destacar la esencia transgresora y re inventiva de las festividades. También, reconocer los elementos históricos, económicos, políticos, educativos, culturales, patrimoniales, entre otros; conservados y renovados en los distintos carnavales.

Por ese motivo, es importante, particularmente en el caso colombiano, que los carnavales se promuevan desde el Ministerio de Cultura y la secretarías locales como una fiesta desde abajo, logrando quebrantar el orden y re inventarlo, alcanzando la expresión de la cultura popular de 
las diversas comunidades, es decir, recuperar y revitalizar festividades desaparecidas, por ejemplo en Bogotá, Cali o Medellín. Así, es posible entender que los fastos son encuentros de la diversidad, los saberes, la vida y la muerte.

Asimismo, distinguir los carnavales desde su dimensión simbólica, de las fiestas que tienen como propósito el sólo entretenimiento. Incluso, reflexionar en torno a la incidencia de la industria del espectáculo en la realización y modificación de ciertos programas o actividades en los carnavales. Por lo tanto, la cuestión de los carnavales puede ser un tema de investigación pertinente, desde los estudios sociales y culturales, al lograr acercarse a las peculiaridades de los habitantes de un pueblo, una ciudad o una región. 